\title{
ON PROGRESSIVE ATROPHY OF THE IRIS WITH FORMATION OF HOLES AND GLAUCOMA
}

\author{
BY \\ Professor G. F. Rochat and Dr. W. Mulder \\ GRONINGEN \\ DURBAN, S.A.
}

IN the literature can be found a small number of cases of atrophy and formation of holes in the iris without any apparent cause. As far as one can judge from the description of these few cases, the majority of which have only been observed in an advanced stage, and could not be examined at distant intervals; there can be no question of congenital malformations. The condition is progressive, so that very large defects in the iris can develop in the course of time. The pupil, even if the greater part of the iris has vanished, remains intact, but in almost all the cases is considerably displaced towards the periphery. In most of the cases on record, glaucoma was observed.

Our knowledge of this remarkable disease is extremely imperfect, firstly, because of its infrequency, but also because its very slow course and the absence of pain do not force the patient to consult the oculist. The disease is, therefore, either casually discovered during an examination for some other complaint, or seen in its last stage, when glaucoma drives the patient to the consulting room. It is very seldom that one has the occasion to see the patient for a long period and still more seldom to make a microscopical examination. As far I am aware this latter has been made only by Bentzen and Leber, Casey Wood, and Licsko. Their results are mainly the same. In all cases the eyes had been removed for absolute glaucoma. No signs of any inflammatory disease were found; the periphery of the iris was firmly adherent to the cornea, and the still existing parts of the iris were atrophic. Licsko attributes the glaucoma to the dissemination of the pigment from the atrophic iris (Pigment-zerstäubung), but partly also to the atrophy of the iris-tissue by which the surface available for the resorption of the intraocular fluid must be considerably diminished (according to the theory of $\mathrm{C}$. Hamburger).

It is apparent that hitherto the most important facts about this disease are insufficiently known. In the first place : is the atrophy of the iris primary and the glaucoma secondary to it, or is the atrophic condition of the iris the result of a very slow running glaucoma? Benzen and Leber were partisans of the first opinion, most authors of later years are inclined to think that at the beginning there is no glaucoma, without being able to give decisive proof.

Secondly, what is the cause of the very striking eccentricity 
of the pupil? It may be the result of a circumscribed shrinking of the iris by some pathological process, in which case the atrophy of the other parts of the iris might be considered to be the consequence of the constant hyperextension of these parts; but it might be just as well explained by assuming a primary atrophy of the iris, in which case the pupil would naturally be drawn to the side where the iris is less atrophic, simply as the result of a disturbance of the equilibrium.

In the following case, which was examined first at the very beginning, accurate and complete notes being taken at that time, and later in an advanced stage, and of which a microscopic examination was made, we were able to ascertain exactly the order in which the different changes took place, and thus to give the answer to the questions mentioned above. The patient was seen by Dr. W. Mulder at Durban for the first time in May, 1917.

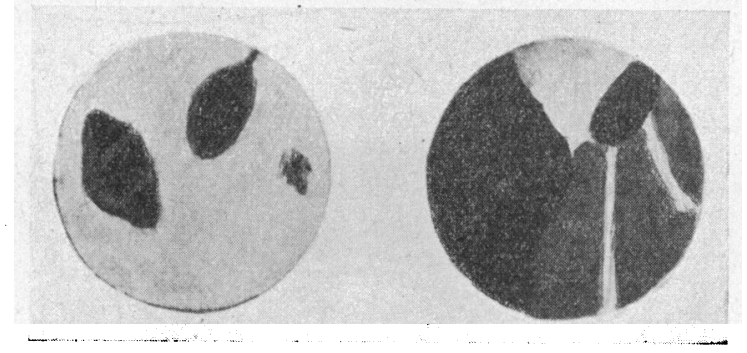

FIG. 1. May 25, 1917.

FIG. 2. May 22, 1923.

Progressive atrophy and hole formation of the iris. Displacement of pupil and ectropion uveae already marked in Fig. 1.

She was then 41 years old, healthy in every respect, except for a light degree of struma, and mother of two healthy children. The Wassermann reaction was negative. She only complained of some fatigue of the eyes, and in a casual way mentioned that the left eye had appeared strange lately and was a little sensitive in sunlight. No accident of any kind had ever happened to this eye. The eye was found normal in every respect; vision $6 / 6$; refraction emmetropic; tension normal; no restriction of the field of vision; fundus normal. Only there was a marked displacement of the pupil towards the temporal side and a little up (Fig. 1). The corresponding part of the stroma had almost disappeared and the everted pigment layer was visible at the temporal side of the pupil as a black line disappearing behind the limbus. On the opposite side, the stroma of the iris was rarefied and at the nasal side there was a complete hole, forming a vertical ellipse, at the bottom of which.two streaks of the pigment layer were still present. Laterally and a little below the pupil there was a small defect of the superficial layer of the iris where the uvea lay exposed. 
This case is the first in which a complete examination for glaucoma was made at an early stage. There can be no doubt that the eye was functionally normal at a time when there already existed a marked degree of atrophy of the iris and hole formation. The latter are therefore the primary affections.

In May, 1923, the patient returned because the eye had become troublesome and sight had gone. There was hardly anything left of the iris (Fig. 2). The pupil was still more pulled towards the periphery ; above there remained a triangular piece of nearly normal iris; the entire nasal half of the iris was occupied by a large hole

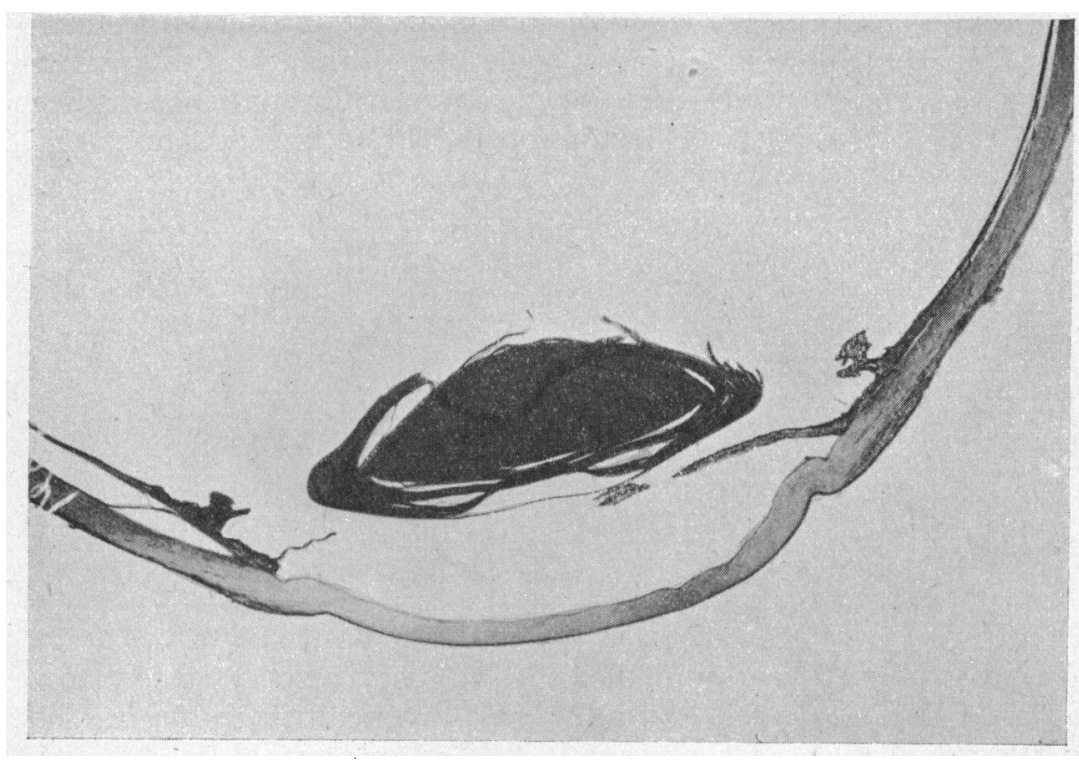

Fig. 3.

Progressive atrophy and hole formation of the iris. Horizontal Section through the largest bole and front of the pupil.

and in the lower part a portion of the pigment layer still existed on which a few narrow streaks of the anterior layer ran in a vertical direction. The eye was painful and blind, the tension +2 , and a deep excavation of the disc was visible. There were no signs of inflammation. The eye was enucleated and sent to Professor Rochat for examination. Microscopically (Fig. 3) the root of the iris was found adherent to the periphery of the cornea in its entire circumference. In the region of the large nasal hole the iris was torn off very near to this adherent portion and in such a way that a broad flap of pigment layer was left attached to the stump floating in the anterior chamber with its free end. In other parts the 
pigment layer was completely torn off together with the stroma of the iris. The peripheral synechia was most developed in the region where the pupil was pulled over to the limbus. In this part, the tissue of the iris firmly attached to the cornea in the angle of the anterior chamber was not rarefied as in other parts, but, on the contrary, was more compact. A new tissue had formed in the angle of the anterior chamber containing many oblong cells with their nuclei parallel to the layers of the cornea. This accumulation of cells was in some spots so abundant that it almost resembled a small sarcoma of the iris-root. The surface of the iris itself in the region of the displaced pupil was covered with a thin layer of the same tissue and over this a hyaloid membrane had formed, carrying a regular layer of endothelium, which could be followed continuously into the endothelium of Descemet's membrane. The posterior layer of the iris, at the place where the pupil is drawn nearest to the limbus, was drawn over to the anterior surface in the form of an ectropion uveae. The small portion of still existing iris was fairly well preserved. There were no undoubted signs of a pre-existing inflammation of the iris, either in the form of a cellular infiltration, or of posterior synechiae, but on the posterior surface of the cornea were a few clusters of cells, carrying uveal pigment. These deposits on Descemet's membrane had not been detected during life; they were not visible with ordinary focal illumination. In the space between the flat part of the ciliary body and the limiting membrane of the vitreous were a few leucocytes charged with pigment and also some red blood corpuscles, probably derived from a small haemorrhage in the retina. The retina was much atrophied in its anterior part but showed no further remarkable changes, nor did the choroid. There were undoubtedly a few signs of a slight recent inflammation, but, as these may be found in the same degree in every case of advanced glaucoma, it is very doubtful if they have any relation to the atrophy of the iris. This is the more improbable, because of the complete lack of signs of recent inflammation in the iris proper.

From the clinical data of this case we can conclude with certainty that the marked degree of atrophy, resulting in the formation of a hole in the iris, of Fig. 1, already existed before a trace of glaucoma. could be detected. Leber and Bentzen's opinion that glaucoma might be the cause of the atrophy of the iris in these cases cannot be sustained.

In the second place this case shows clearly that the displacement of the pupil cannot be the effect of a primary atrophy of some adjacent part of the iris, for though at the time of the first examination the hole in the iris was not very large, the pupil was already markedly pulled to one side and there was a visible ectropion uveae in the corresponding region to explain this condition. 
From pathological examination as well as from the clinical data one gets the impression that the principal factor in the process is the soldering together of the root of the iris with the periphery of the cornea beginning at a circumscribed spot and leading to displacement of the pupil. In a second stage the pulling over of the iris causes distension of the anterior layer of the opposite part, resulting in atrophy, and, finally, tearing of the stroma, alone or together with the pigment layer. The appearance of the holes is the most conspicuous symptom of the disease, and, therefore, first detected. The slowly progressing obliteration of the angle of the anterior chamber, when completed, causes the final stage in which glaucoma destroys the vision.

In the present case the microscopic examination gives no definite clue to the cause of the circumscribed obliteration of the angle of the anterior chamber. It is, of course, very probable that the newly formed compact tissue, the shrinking of which causes the obliteration of the angle in the affected area, is the result of some inflammatory process. But neither clinical nor pathological examination showed definite symptoms of such a process. It is not altogether improbable that, if one could examine a case in a still earlier stage with slit-lamp and high magnification one might succeed in detecting such symptoms. In this relation it may be emphasized that de la Vega observed hole formation in the iris subsequent to a syphilitic infection. It is true that in this case no inflammation of the anterior parts could be detected clinically, but there existed an old retino-choroiditis peripherica. Also in a case described by Harms in which, however, glaucoma was present, fine deposits on the posterior surface of the cornea were found that might possibly be interpreted as signs of inflammation.

As there is but little chance that anyone should get an opportunity to make a microscopical examination of a case at the very beginning, this point will probably not be elucidated in the near future.

\section{LITERATURE}

1. Arnold.- "Ein neuer Fall von fortschreitender Irisatrophie mit Lueckenbildung. "Klin. Monatsbl. f. Augenheilk., p. 724, 1923.

2. Licsko. - " Durch Irisatrophie hervorgerufenes Glaucom." Ibidem, p. 456, 1923.

3. Larsson.- "Zur Kenntniss der erworbenen Irisatrophie." Ibidem, p. 510, 1920.

4. de la Vega.- " Fortschreitende Atrophie der nicht entzuendeten Iris nach Chorio-retinitis syphilitica." Ibidem, p. 44, 1923.

5. Casey Wood. - " Progressive primary atrophy and almost complete disappearance of the right iris." Ophthalmoscope, p. 858, 1910.

6. Lane.--"Primary progressive atrophy of the iris." Ophthal. Record, 1917.

7. Harms. - "Spontane Lueckenbildung der Iris ohne mecharische Zerrung." Klin. Monatsbl.f. Augenheilk., p. 522, 1903.

8. Bentzen and Leber.- "Ueber Filtration aus der vorderen Kammer, etc." Arch. f. Ophthal., 41, 3, p. 229, (Versuch VI.) 